\title{
LncRNA SNHG5 promotes the progression of osteosarcoma by sponging the miR-212-3p/SGK3 axis
}

Cheng Ju1,2,3+, Ruihao Zhou ${ }^{1,4+}$, Jun Sun ${ }^{1}$, Feifei Zhang ${ }^{1}$, Xiaofeng Tang ${ }^{1}$, Kaddie Kwok Chen ${ }^{1}$, Junliang Zhao ${ }^{1,4}$,

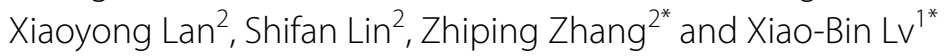

\begin{abstract}
Background: Long non-coding RNA (InCRNA) SNHG5 has been found to play an important role in tumors. Nevertheless, the function and mechanism of IncRNA SNHG5 in osteosarcoma (OS) remains unclear. The purpose of this study was to investigate whether IncRNA SNHG5 can regulate the occurrence and development of OS cells.

Methods: We performed quantitative real time PCR to detect the expression of IncRNA SNHG5 in OS cells. 143B, MG63 (knockdown) and U2OS, U2R (overexpression) cell lines were chosen for the function study of SNHG5. The effect of SNHG5, miR-212-3p, and SGK3 in OS cells was explored by MTT assays, clony formation, flow cytometry, transwell assays, wound healing assays, and cell spreading assays. Quantitative real-time PCR, Western blot analysis and luciferase assays were used to detect the interaction between IncRNA SNHG5 and miR-212-3p.

Results: In this study, knockdown of IncRNA SNHG5 suppressed the growth and metastasis of OS cells, whereas the overexpression of SNHG5 produced an opposite result. Mechanistically, IncRNA SNHG5 functions as a sponger against miR-212-3p and suppresses the miR-212-3p/SGK3 signaling pathway. Introduction of miR-212-3p mimics or inhibitors reverses SNHG5 overexpression or silences the exerted tumor promoting or suppressing effect. In addition, our results showed that the function of SNHG5 can be rescued by miR-212-3p and can regulate the growth and metastasis of OS cells via SGK3, the downstream target of miR-212-3p.

Conclusions: In summary, our study demonstrated that IncRNA SNHG5 can regulate the proliferation and metastasis of OS cells through the miR-212-3p/SGK3 axis. This axis may provide a new target for future clinical treatment.
\end{abstract}

Keywords: IncRNA SNHG5, miR-212-3p, Osteosarcoma, SGK3, Cell proliferation, Cell invasion and migration

\section{Background}

Osteosarcoma (OS) is the most common primary malignant bone tumor with the highest incidence in adolescents, often with early metastasis and lung metastases [1, 2]. To date, OS patients regularly suffer from poor clinical prognosis [3-5]. Therefore, it is significant to illustrate

\footnotetext{
*Correspondence: ndsfy001425@ncu.edu.cn; nclvxiaobin@sina.cn

${ }^{\dagger}$ Cheng Ju and Ruihao Zhou contributed equally to this work

1 Jiangxi Key Laboratory of Cancer Metastasis and Precision Treatment,

The Third Affiliated Hospital of Nanchang University, 128 Xiangshan

Northern Road, Nanchang 330008, Jiangxi, People's Republic of China

${ }^{2}$ Department of Orthopedics, The Third Affiliated Hospital of Nanchang

University, 128 Xiangshan Northern Road, Nanchang 330008, Jiangxi,

People's Republic of China

Full list of author information is available at the end of the article
}

the molecular mechanism of OS to help provide new directions and methods for the treatment of OS patients.

About $70 \%-80 \%$ of the genome can be transcribed into RNAs in humans, but only $2 \%-3 \%$ of RNAs can be transcribed to encode proteins [6]. LncRNA refers to RNA larger than 200 nucleotides in length that do not have the ability to code protein $[7,8]$. LncRNAs influence various biological processes, including chromatin organization, epigenetic regulation, gene transcription and translation, RNA turnover, and genome defense $[9,10]$. In the recent years, increasing studies have found that lncRNAs play an extremely important role in the occurrence and development of tumors [11-13]. At present, a significant number of lncRNAs have been discovered to play an

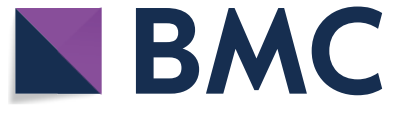

(c) The Author(s) 2018. This article is distributed under the terms of the Creative Commons Attribution 4.0 International License (http://creativecommons.org/licenses/by/4.0/), which permits unrestricted use, distribution, and reproduction in any medium, provided you give appropriate credit to the original author(s) and the source, provide a link to the Creative Commons license, and indicate if changes were made. The Creative Commons Public Domain Dedication waiver (http://creativecommons.org/ publicdomain/zero/1.0/) applies to the data made available in this article, unless otherwise stated. 
important role in OS. For instance, the upregulation of lncRNA MALAT1, TUG1, HULC, and SNHG12 promote the tumorigenesis of OS [14-17]. Conversely, lncRNA loc285194, TUSC7, and HIF2PUT serve as tumor suppressor genes in OS [18-20].

MicroRNAs (miRNAs) are small non-coding RNA molecules, generally 20-22 nucleotides long, that can mediate the inhibition of transcription and degradation of mRNA via their 3'-untranslated region (3'-UTR) [21]. Several miRNAs have been reported as a suppressor gene or tumor-promoting gene that regulates the proliferation, migration, and invasion of tumors [22, 23]. Existing research shows that the interaction between lncRNA and miRNA is critically important in the progression of cancer. LncRNAs have been also confirmed to regulate the progression of cancers by sponging miRNA [24, 25]. Currently, lncRNA small nucleolar RNA host gene 5 (SNHG5) has been found to act as a tumor-promoting gene in bladder cancer and colorectal cancer [26, 27] and a suppressor gene in gastric cancer [28]. Moreover, SNHG5 can also modulate the progression of cancer by competitively binding to miRNA [29]. These studies show that SNHG5 plays a significant role in a variety of different cancers [26-28, 30-32]. However, the function of SNHG5 in osteosarcoma remains unclear, thus driving us to explore the role of SNHG5 in OS.

In the present study, our results demonstrate that the overexpression of SNHG5 can promote the migration, invasion, and proliferation of OS, whereas knockdown of SNHG5 reduces the migration, invasion, and proliferation of OS cells. Subsequently, our study found that the SNHG5/miR-212-3P/SGK3 axis is critical in the progression of OS.

\section{Materials and methods \\ Cell culture}

The human OS cell lines (143B, U2OS, U2R, MG63) were kindly provided by professor Kang [33]. All of the OS cells were cultured in DMEM medium supplemented with $10 \%$ fetal bovine serum (FBS, Gibco). 293T cells were cultured in DMEM medium supplemented with $10 \%$ FBS (BI). All cells grew in a $37^{\circ} \mathrm{C}$ humidified incubator with $5 \% \mathrm{CO}_{2}$.

\section{Cell transfection}

The overexpression plasmid of SNHG5 (pcDNASNHG5) was constructed by inserting the full-length SNHG5 sequences into the pcDNA3.1 vector. The sequence of sh-SNHG5 was cloned into pLKO.1 vector and constructed a SNHG5 knockdown stable cell line for further experiments. Primers of sh-SNHG5 are listed in Table 1; SNHG5 siRNA, SGK3 siRNA, miRNA mimics and inhibitors were purchased from
Table 1 The primer sequences were used in this article

\begin{tabular}{|c|c|}
\hline Gene & Sequence \\
\hline sh-SNHG5-1-F & $\begin{array}{l}\text { 5'-CCGGGAGGCCAGATTGTCTTGGACTCGAGTCCA } \\
\text { AGACAATCTGGCCTCTTTTTTGGTACC-3' }\end{array}$ \\
\hline sh-SNHG5-1-R & $\begin{array}{l}\text { 5'-AATTGGTACCAAAAAAGAGGCCAGATTGTCTTG } \\
\text { GACTCGAGTCCAAGACAATCTGGCCTC-3' }\end{array}$ \\
\hline sh-SNHG5-2-F & $\begin{array}{l}\text { 5'-CCGGGCAACGATTTCTGGCTAGTCTCGAGACTAG } \\
\text { CCAGAAATCGTTGCTTTTTTGGTACC-3' }\end{array}$ \\
\hline sh-SNHG5-2-R & $\begin{array}{l}\text { 5'-AATTGGTACCAAAAAAGCAACGATTTCTGGCTAG } \\
\text { TCTCGAGACTAGCCAGAAATCGTTGC-3' }\end{array}$ \\
\hline SNHG5-F & 5'-CGCTTGGTTAAAACCTGACACT-3' \\
\hline SNHG5-R & 5'-CCAAGACAATCTGGCCTCTATC-3' \\
\hline SGK3-F & 5'-CCAGGAGTGAGTCTTACAG-3' \\
\hline SGK3-R & 5'-CCAGCCACATTAGGATTA-3' \\
\hline$\beta$-Actin - $f$ & 5'-GCCCTGGCACCCAGCACAAT-3' \\
\hline$\beta$-Actin -R & 5'-GGAGGGGCCGGACTCGTCAT-3' \\
\hline ZEB1-f & 5'-CAGGCAGATGAAGCAGGATG-3' \\
\hline ZEB1-R & 5'-CAGCAGTGTCTTGTTGTTGTAG-3' \\
\hline Twist-f & 5'-CCAGGTACATCGACTTCCTCTA-3' \\
\hline Twist- $R$ & 5'-CCATCCTCCAGACCGAGAA-3' \\
\hline FLII-F & 5'-CCTCCTACAGCTAGCAGGTTATCAAC-3 \\
\hline FLII-R & 5'-GCATGTGCTGGATATATACCTGGCAG-3 \\
\hline BAD-F & 5'-ATGTTCCAGATCCCAGAGTTTG-3' \\
\hline BAD-R & 5'-ATGATGGCTGCTGCTGGTT-3' \\
\hline bcl-xl-F & 5'-GCATATCAGAGCTTTGAACAGG-3' \\
\hline$b c|-x|-R$ & 5'-GAAGGAGAAAAAGGCCACAATG-3' \\
\hline bim-F & 5'-AAGGTAATCCTGAAGGCAATCA-3' \\
\hline bim-R & 5'-CTCATAAAGATGAAAAGCGGGG-3' \\
\hline AlP4-F & 5'-GCAGCAGTTTAACCAGAGATTC-3' \\
\hline AlP4-R & 5'-GTGTGTTGTGGTTGACGAAATA-3' \\
\hline GSK3- $\beta-F$ & 5'-AGGAGAACCCAATGTTTCGTAT-3' \\
\hline GSK3- $\beta-R$ & 5'-ATCCCCTGGAAATATTGGTTGT-3' \\
\hline
\end{tabular}

GenePharma Co. Ltd. (SuZhou, China). Lipofecmine 2000 and Lipofectamine ${ }^{\circledR}$ RNAiMAX were used as the transfection reagents according to the manufacturer's instructions.

\section{Transwell assay}

Transwell chambers were inserted in 24-well plates. Firstly, cells were washed with serum free media and treated with mitomycin c $(10 \mu \mathrm{g} / \mathrm{ml}$ for $30 \mathrm{~min})$. The upper chamber of each well was seeded with $1 \times 10^{5}$ cells with serum-free DMEM medium. DMEM containing $10 \%$ fetal bovine serum was added to the lower chamber. To assess cell invasion, $50 \mu \mathrm{l}$ diluted Matrigel (BD Biosciences, Franklin Lakes, NJ) was added to the upper chamber of the transwell. The 143B, MG63, U2R and $\mathrm{U} 2 \mathrm{OS}$ cells were allowed to migrate for $22 \mathrm{~h}$ and invade for $24 \mathrm{~h}$. At the specified time, the cells that had migrated or invaded were fixed, stained, and counted. 


\section{MTT assay}

MTT assay was used to detect the viabilities of OS cells. Cells (about $1 \times 10^{4}$ cells/well) were placed in 96-well plates and seeded for $24 \mathrm{~h}, 48 \mathrm{~h}, 72 \mathrm{~h}$. Subsequently, $4 \mathrm{~h}$ before the specified time, MTT solution was added before adding DMSO to dissolve. Finally, cell viability was detected at a wavelength of $450 \mathrm{~nm}$ according to the manufacturer's instructions. Each group was repeated three times to ensure accuracy of the results.

\section{Cell spreading assay}

Cells were centrifuged and resuspended, before allowing to spread on a matrigel-coated plate in a $37{ }^{\circ} \mathrm{C}$ humidified incubator with $5 \% \mathrm{CO}_{2}$. After $1.5 \mathrm{~h}$, cells that did not adhere were washed out with PBS, and the adherent cells were fixed, stained, and counted.

\section{Flow cytometry}

Cell apoptosis was determined using Annexin V-FITC/ PI kit (Cat. no: KGA108, Keygen, China). After $48 \mathrm{~h}$ the transfection, OS cells were first washed with PBS and resuspended in $500 \mu \mathrm{l}$ of $1 \times$ binding buffer. Next, $5 \mu \mathrm{l}$ of Annexin V-FITC and $5 \mu \mathrm{l}$ of PI were added for $20 \mathrm{~min}$ in the dark at room temperature. Finally, flow cytometry (Becton-Dickinson, USA) was performed to detect the number of apoptotic cells according to the Manufacturer's instructions.

\section{Clony formation}

After transfection of siSNHG5 or pcDNA-SNHG5 for $12 \mathrm{~h}$, OS cells were seeded in 6-well plates at a density of 500 cells per well and maintained for 10 days. Cells were immobilized with paraformaldehyde for $20 \mathrm{~min}$, stained with crystal violet for $30 \mathrm{~min}$ and washed with PBS for 3 times. The stained cell colonies were counted.

\section{Wound healing assays}

Wound-healing assays were performed to examine the migratory ability of cells. Firstly, cells were washed with serum free media and treated with mitomycin c $(10 \mu \mathrm{g} / \mathrm{ml}$ for $30 \mathrm{~min})$. Transfected cells were cultured in 12-well plates for $24 \mathrm{~h}$. The cell monolayer was scratched using a $20-\mu \mathrm{l}$ pipette tip, and the cells were cultured for an additional $24 \mathrm{~h}$. The progression of migration was observed and photographed at 0,12 , and $24 \mathrm{~h}$ after wounding. The distance between the two edges of the scratch was measured and calculated.

\section{Real-time PCR}

Total RNA was extracted from OS cell lines with TRIzol reagent (Invitrogen, Carlsbad, CA, USA) according to the manufacturer's instructions. PrimeScript ${ }^{\mathrm{TM}} \mathrm{RT}$ reagent Kit with gDNA Eraser (TaKaRa, China) was used in order to obtain cDNA. Quantitative real-time PCR (qRT-PCR) was performed using SYBR Select Master Mix for CFX (Invitrogen) and the CFX Connect Real-time PCR system (BioRad) at $95{ }^{\circ} \mathrm{C}$ for $15 \mathrm{~s}$, followed by 40 cycles of $95{ }^{\circ} \mathrm{C}$ for $5 \mathrm{~s}$, and $60{ }^{\circ} \mathrm{C}$ for $34 \mathrm{~s}$. The data were analyzed with the $2^{-\Delta \Delta \mathrm{Ct}}$ method. All of primers are listed in Table 1.

\section{Western blot analysis}

Cells were homogenized in RIPA protein lysis buffer supplemented with protease inhibitors on ice for $30 \mathrm{~min}$ before centrifuging at $12,000 \mathrm{~g}$ for $20 \mathrm{~min}$ at $4{ }^{\circ} \mathrm{C}$. The BCA protein assay kit (Pierce, Rockford, IL, USA) was used to measure protein concentration. The total protein extracts were separated by $10 \%$ SDS-PAGE and transferred to PVDF membranes (Millipore, USA). The membranes were blocked with 5\% non-fat milk for $2 \mathrm{~h}$. Afterwards, the membranes were incubated overnight at $4{ }^{\circ} \mathrm{C}$ with the corresponding antibody. Subsequently, the membranes were washed with PBST three times and incubated with secondary antibodies (anti-Rabbit, antiMouse) for $2 \mathrm{~h}$. After incubating the anti-Rabbit and antiMouse antibodies, the membranes were washed with PBST 3 times and then developed with ECL Western Blotting Substrate. $\beta$-actin was used as a control.

\section{Luciferase assay}

The SNHG5 3'-UTRs were constructed into pMIRreporter plasmids. The SNHG5 and miR-212-3p mimics or NC mimics were co-transfected into $293 \mathrm{~T}$ cells with Lipofectamine 2000 (Invitrogen), respectively. The Luciferase Reporter Assay System was used for to detecting the luciferase activity.

\section{Statistical analysis}

All of statistical analyses were executed using SPSS 16 software (SPSS, Inc, Chicago, IL, USA). The P-values were calculated using a one-way analysis of variance (ANOVA). A P-value of $<0.05$ was considered to indicate a statistically significant result.

\section{Results}

LncRNA SNHG5 regulates the proliferation and clony formation of osteosarcoma

We analyzed the data from GEO database (https://www. ncbi.nlm.nih.gov/geo/query/acc.cgi?acc=GSE70415, GSE49003, GSE39058) to investigate the clinical relevance of lncRNA SNHG5 in osteosarcoma. Data showed upregulation of lncRNA SNHG5 in osteosarcoma compared to hMSCs (GSE70415, Fig. 1a) and metastatic osteosarcoma compared to non-metastatic (GSE49003 


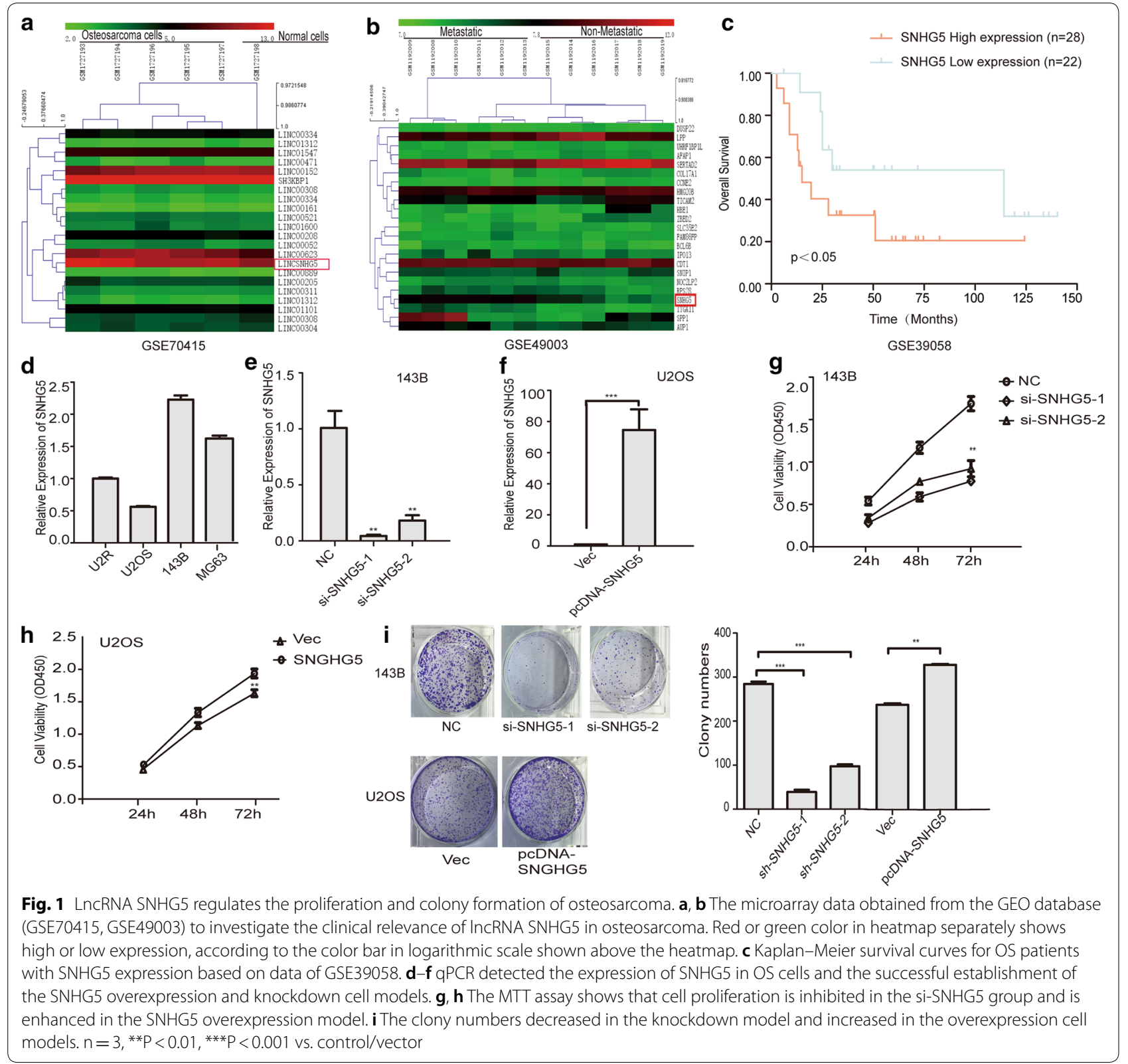

Fig. 1b). Besides, the high expression level of lncRNA SNHG5 is correlated with the patient poor diagnosis (GSE39058, Fig. 1c). To explore the biological function of lncRNA SNHG5 in OS, the expression level of SNHG5 in OS cells (143B, U2OS, U2R, MG63) was detected by real-time PCR (RT-PCR). According to the expression of SNHG5 (Fig. 1d), we transfected siRNAs or the full length of SNHG5 into 143B and U2OS cells, respectively. Efficient silencing of SNHG5 using siRNAs was confirmed using qRT-PCR (Fig. 1e). In addition, Overexpression of SNHG5 increased its RNA level by 70 fold in comparison with the empty vector control (Fig. 1f). The results of the MTT assay and the clony formation assay showed that knockdown of SNHG5 decreased the proliferation of 143B cells, while overexpression of SNHG5 promoted the proliferation of U2OS cells (Fig. 1g-i).

\section{LncRNA SNHG5 regulates the apoptosis of osteosarcoma cells via caspase pathways}

Flow cytometry was utilized to determine the effect of SNHG5 on the apoptosis of OS cells. As shown in Fig. 2a, knockdown of SNHG5 significantly increased the apoptosis of 143B cells. Next, to examine whether knockdown of SNHG5 activated the caspase pathways, 

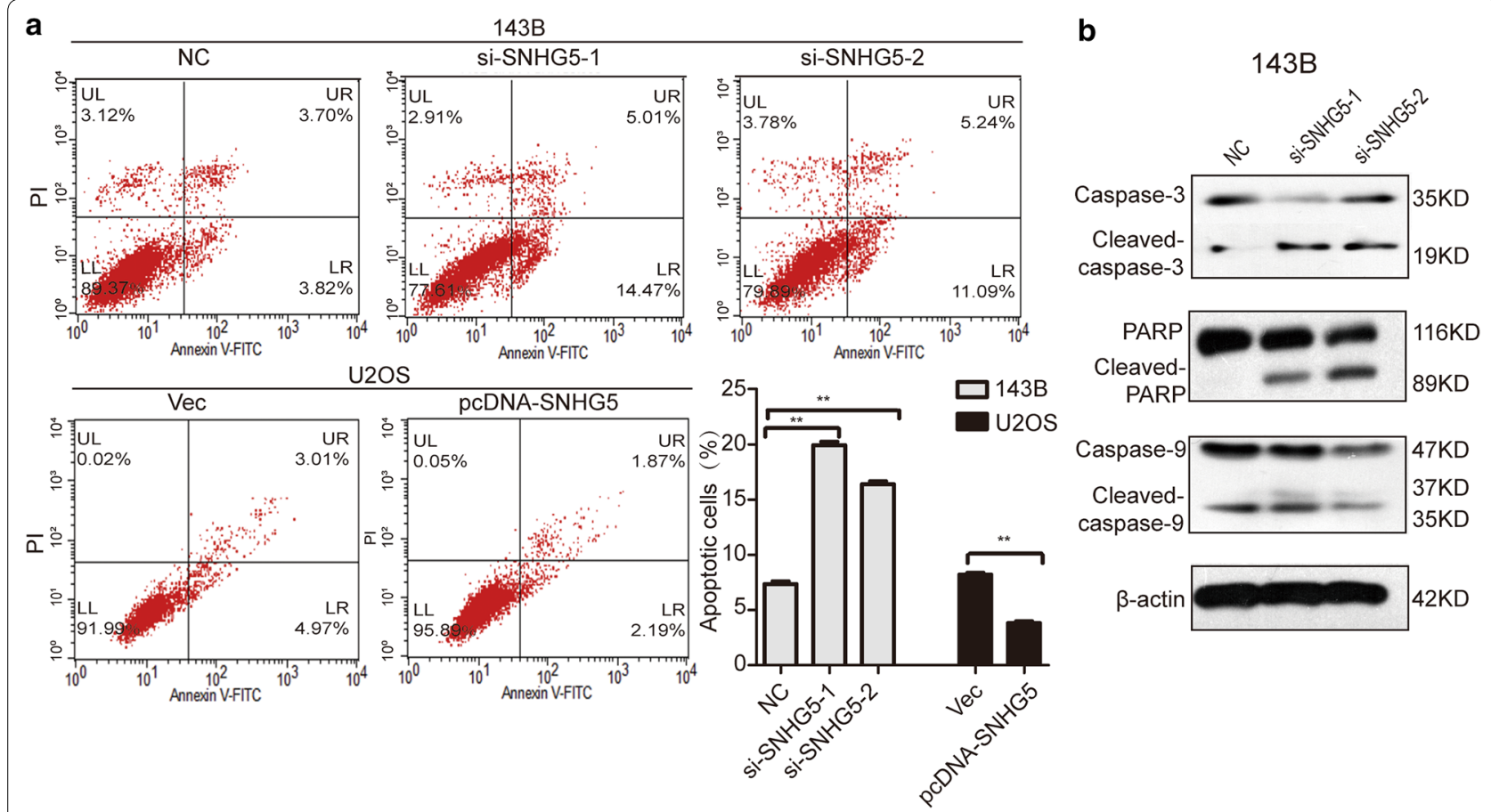

Fig. 2 LncRNA SNHG5 regulates the apoptosis of osteosarcoma cells via caspase pathways. a Cell apoptosis results were tested by flow cytometry. b The protein expression of caspase3, cleaved caspase-3, PARP, and caspase- 9 was determined by western-blotting analysis. $n=3$, ${ }^{* *} P<0.01$ compared with NCNector

western blotting showed that caspase-3, caspase-9, and PARP were activated (Fig. 2b). This suggests that SNHG5 expression can affect the expression of apoptosis and its associated genes and proteins.

\section{LncRNA SNHG5 regulates the migration and invasion of osteosarcoma cells via the EMT process}

To investigate the role of SNHG5 during cell metastasis and explore the relation of SNHG5 in the EMT process, we performed transwell assays, wound healing assays, and cell spreading assays. The results of the transwell assays and wound healing assays revealed that knockdown of SNHG5 significantly reduced the migration and invasion of 143B cells (Fig. 3a, b). Conversely, overexpression of SNHG5 substantially promoted the migration and invasion of U2OS cells (Fig. 3a, b). Because spreading capacity is one of the important traits contributing to metastasis, cell spreading assays were then conducted with transfected cells. Figure $3 \mathrm{c}$ shows that SNHG5 siRNA decreased cell spreading while overexpression of SNHG5 increased it. EMT plays a critical role in the migration and invasion of tumors, as it promotes tumor cell migration and invasion [34, 35]. Thus, we next determined whether EMT related markers were altered in our study. The results showed that the protein expression of $\mathrm{N}$-cadherin, Vimentin, and $\beta$-catenin significantly decreased while E-cadherin expression increased when SNHG5 was silenced, in comparison with the si-NC group (Fig. 3d). Compared with the empty vector group, contrasting results were found in U2OS cells after SNHG5 overexpression (Fig. 3d). Besides, the mRNA expression of Twist and ZEB1 transcriptional factors changed paralleled to SNHG5 like other EMT markers (Fig. 3e). Thus, these results demonstrated that lncRNA SNHG5 was involved in the EMT process and knockdown of SNHG5 inhibits the EMT process in OS cells. Besides, we confirmed the function of lncRNA SNHG5 in other two OS cells via MTT, clony formation, flow cytometry, transwell assay (MG63, U2R). The results showed LncRNA SNHG5 regulated the proliferation, migration and invasion of osteosarcoma cells (Additional file 1: Figure S1).

\section{LncRNA SNHG5 acted as a direct target of the miR-212-3p}

The ceRNA hypothesis presumes that specific lncRNA can actas sinks for pools of active miRNAs [36, 37], such as Long noncoding RNA GAPLINC promotes gastric cancer cell proliferation by acting as a molecular sponge of miR-378 to modulate MAPK1 expression [38], Long noncoding RNA DANCR promotes colorectal cancer proliferation and metastasis via miR-577 sponging [39] To further explore the mechanism of SNHG5 


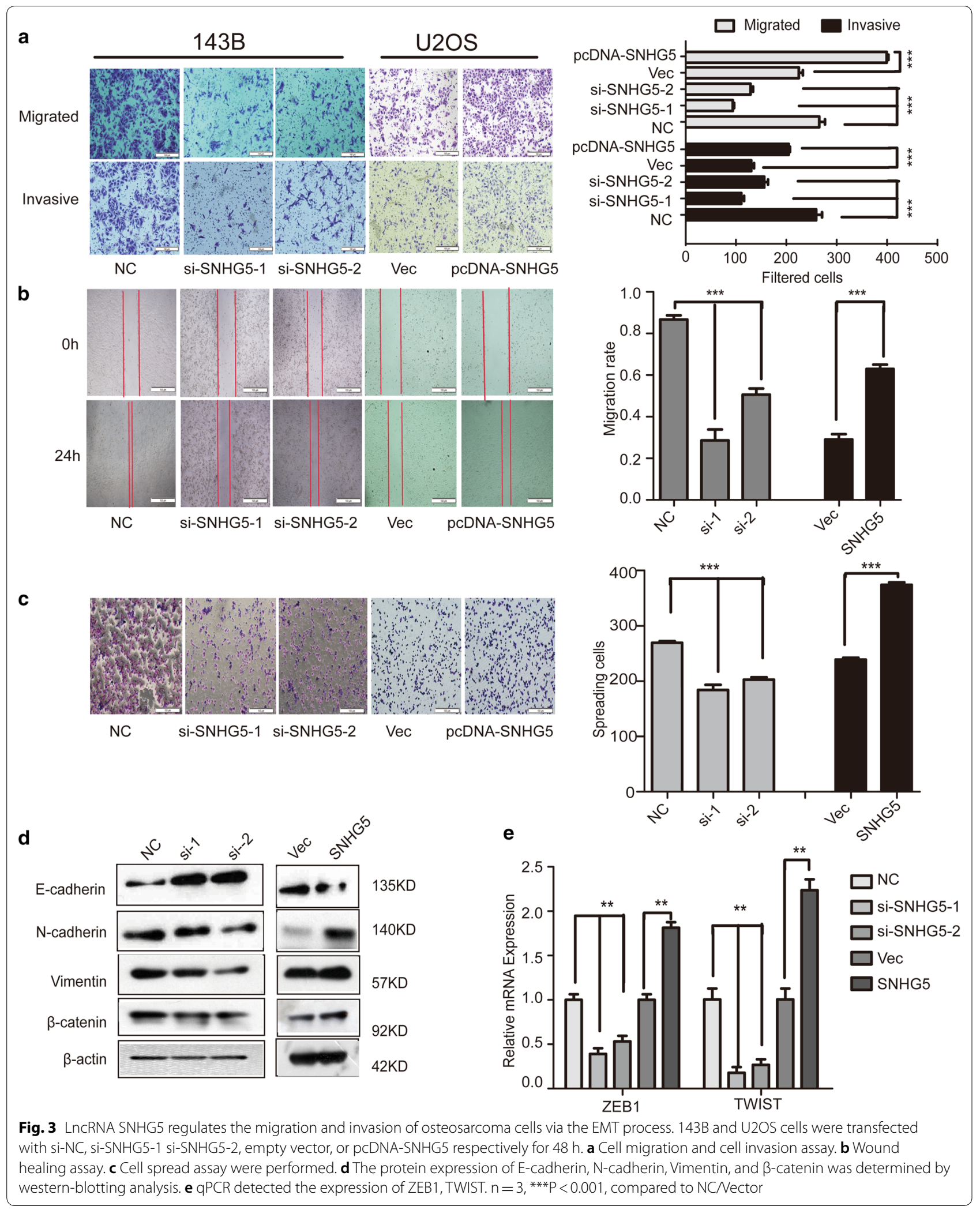


in osteosarcoma, an online bioinformatics software, Starbase (http://starbase.sysu.edu.cn/), was used to predict the target sites of lncRNA SNHG5 and miR-212-3p miRNA (Fig. 4a). Simply, we inserted the gene symbol of lncRNA SNHG5 into database of Starbase v2.0 in order to find possible target miRNAs and the system showed that lncRNA SNHG5 may interact with miR212-3p. RT-PCR results reveal that the expression of SNHG5 reduced after transfection of miR-212-3p mimics (Fig. 4b). Conversely, knockdown of miR-212-3p significantly increased the expression of SNHG5 (Fig. 4c). Subsequently, we constructed plasmids expressing a chimera gene SNHG5-luciferase. Then we transfected cells with control miRNAs (miR-NC) or with mir-212-3p mimic. This latter one reduced the luciferase expression (Fig. 4d). SGK3 has been reported to be an important tumorpromoting gene and the target gene of miR-212-3p in glioblastoma cells [40-42]. Q-PCR results showed that transfecting miR-212-3p mimics, si-SGK3 and si-SNHG5 strongly reduced the expression of SGK3 (Fig. 4e). The above results showed that SNHG5 might act as a direct target of miR-212-3p.
LncRNA SNHG5 as a molecular sponge of miR-212-3p to further promote the growth and migration of OS

Next, we explored the interaction of SNHG5 and miR$212-3 p$ in OS cell growth, migration, and invasion. The results of MTT and transwell assays showed that overexpression of miR-212-3p could reduce the growth, invasion, and migration of pcDNA-SNHG5 (Fig. 5a, b). Conversely, knockdown of miR-212-3p significantly increased the cell proliferation, invasion, and migration abilities of OS cells. In fact, this increase could be restored by co-transfecting si-SNHG5-mixture with miR212-3p inhibitors (Fig. 5c, d). In addition, the protein expression of EMT markers in two rescue assays was also verified (Fig. 5e, f).

\section{LncRNA SNHG5/miR-212-3p/SGK3 axis regulate the progression of osteosarcoma}

Recently, SGK3 has been reported to be an important tumor-promoting gene [40, 41]. Moreover, SGK3 has been recently published as the target gene of miR212-3p in glioblastoma cells [42]. However, the function of SGK3 in OS has not been confirmed. Knockdown of

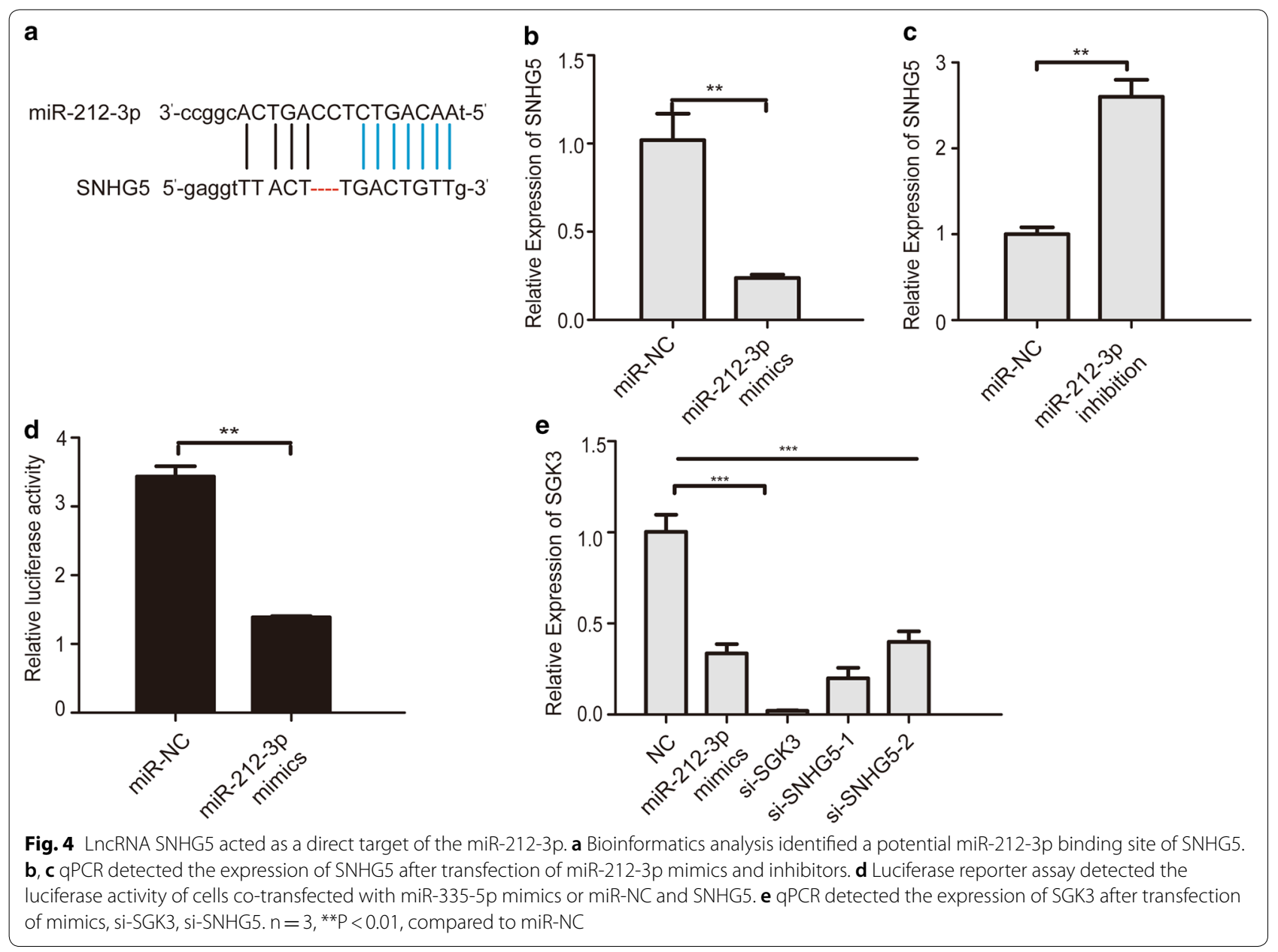




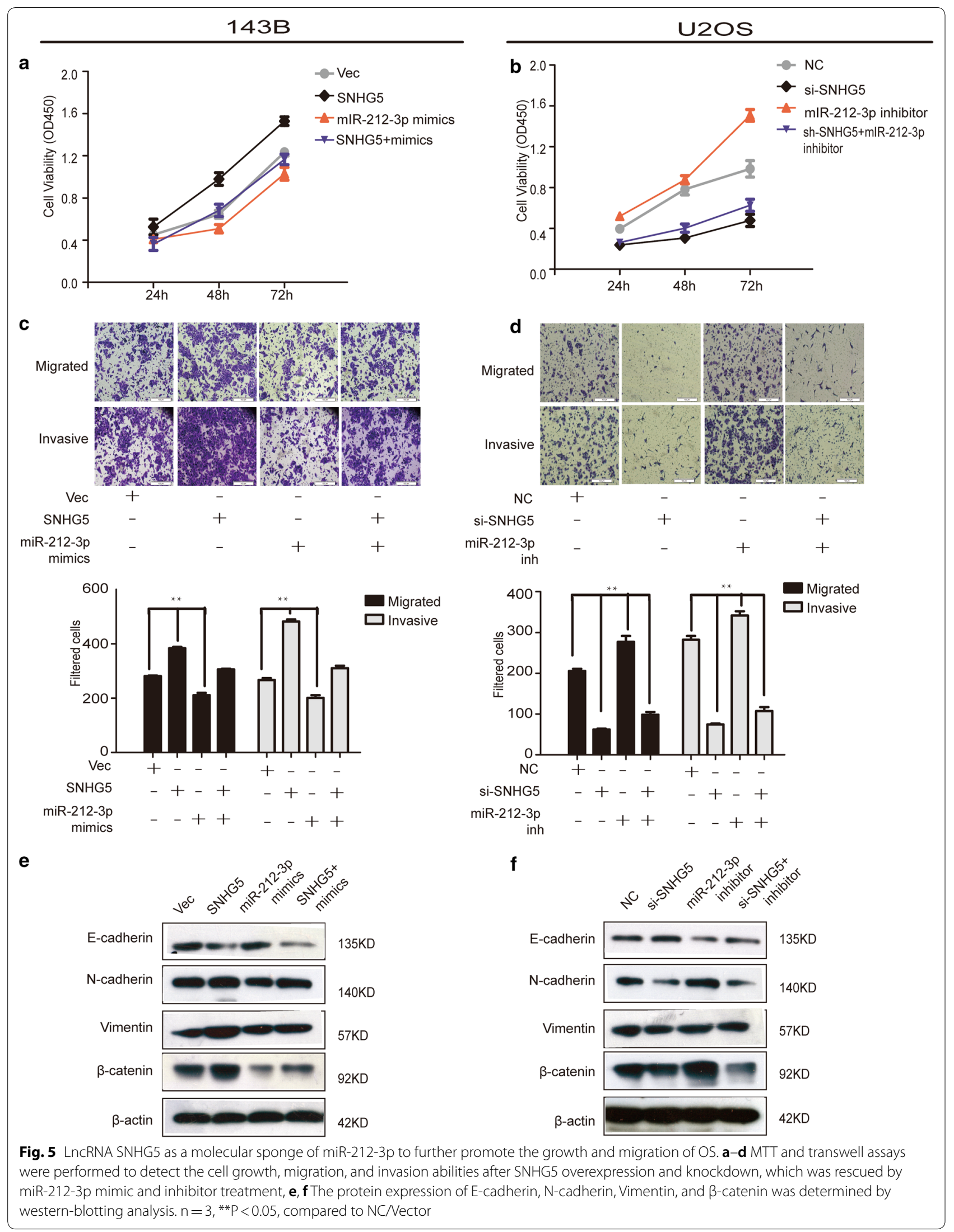


SGK3 decreased the migration, invasion and growth of OS (Fig. 6a, b). Furthermore, we found that the expression of our above mentioned EMT markers significantly decreased when SGK3 was silenced, while E-cadherin expression was increased-which was consistent with SNHG5 expression (Fig. 6c, d). The above results showed that lncRNA SNHG5 might regulate the progression of OS through the miR-212-3p/SGK3 axis. Expression of other apoptosis associated genes were performed especially as previous researchers have been shown to change with SGK3 knockdown such as Bad, Bim, Bcl-xL [43-45]. The results showed that the expression of SGK3 was consistent with Bcl-xl while opposite to Bad and Bim (Fig. 6e). Then we detected the expression of SGK3's direct targets such as AIP4, FLII, GSK3 $\beta$ [43-45]. Results showed that the expression of these targets was consistent with SGK3 (Fig. 6e). The results of transwell assays showed that overexpression of SNHG5 and inhibition of miR-212-3p could extenuate the reduction of invasion, and migration of si-SGK3 (Fig. 6f), which showed LncRNA SNHG5/miR-212-3p/SGK3 axis regulate the progression of osteosarcoma. Above all, we illustrated the pathway diagram of LncRNA SNHG5 / miR-212-3p/ SGK3 axis in osteosarcoma (Fig. 7).

\section{Discussion}

OS is the most common malignant bone tumor in adolescents. Between 70 and $80 \%$ of patients are 10 to 25 years old, with an annual incidence of 1-3/100,000 [46, 47]. Currently, the 5-year survival rate of OS patients is still in the range of $60 \%$ to $70 \%$ due to the unclear pathogenesis of OS [48]. Thus, it is vital that the molecular mechanism of OS is evident to improve treatment.

Many previous studies have elaborated on the functions of lncRNA SNHG5 in detail. For example, SNHG5 promotes colorectal cancer cell survival by counteracting STAU1-mediated mRNA destabilization [27]. SNHG5 is also associated with poor prognosis of bladder cancer, and promotes bladder cancer cell proliferation through targeting P27 [26]. Long non-coding RNA SNHG5 also suppresses gastric cancer progression by trapping MTA2 in the cytosol [28], in addition to being a new biomarker in malignant melanoma [31]. These studies demonstrate the importance of SNHG5 in cancers. In our study, we found that overexpression of SNHG5 promoted OS cell growth. Yet, knockdown of SNHG5 inhibited OS cell proliferation and induced apoptosis through activating cleaved-caspase-3, cleaved-caspase-9, and cleaved-PARP. However, it has been demonstrated that mesenchymal stromal cells, from which osteosarcoma cells originate. Interestingly, Alessio et al. [49] found cells are prone to senescence rather than apoptosis even after high exogenous stress.
This is also worth further exploring. In addition, EMT plays a critical role in the migration and invasion of tumors, as it promotes tumor cell migration and invasion [34, 35]. E-cadherin acts as an epithelial marker that is lowly expressed in tumors, whereas vimentin and $\beta$-catenin are interstitial markers highly expressed in tumors [50]. As key proteins of EMT, upregulation of E-Cadherin and downregulation of vimentin and $\beta$-catenin are considered characteristic expressions of EMT. In the present study, western blotting revealed that the knockdown of SNHG5 increased the expression of E-cadherin and reduced the expression of Vimentin and $\beta$-catenin in OS cells. The overexpression of SNHG5 produced an opposite result.

In recent years, the competing endogenous RNA (ceRNA) hypothesis has been extensive promoted, and some studies have confirmed the interaction of lncRNA and miRNA in multiple cancers $[24,25]$. In previous studies, lncRNA SNHG5 was found to be able to interact with miRNA. For example, long non-coding RNA SNHG5 regulates gefitinib resistance in lung adenocarcinoma cells by targeting the miR-377/CASP1 axis [32]. The lncRNA SNHG5/miR-32 axis regulates gastric cancer cell proliferation and migration by targeting KLF4 [29], in addition to regulating imatinib resistance in chronic myeloid leukemia via MiR-205-5p [30]. To examine whether existing miRNA can bind to lncRNA SNHG5 in OS cells, we used an online bioinformatics software, Starbase, to predict the sites of lncRNA SNHG5 and miRNA, in which miR-212-3p was chosen for further study. Interestingly, we found that researcher [51] evaluated the expression of miR-212-3p in OS tissues by RT-qPCR with the result showing a substantial decrease of miR-212-3p expression in OS tissues compared to that in normal tissues, which was consistent with our results.

Subsequently, luciferase report assays and RT-PCR results showed that miR-212-3p can be combined with SNHG5 to reduce the activity of SNHG5. However, rescue assays revealed that miR-212-3p mimics suppress the growth and metastasis of pcDNA-SNHG5, and that its the restoration can be induced by co-transfecting the si-SNHG5-mixture with miR-212-3p inhibitors.

SGK3 has been found in others cancers as a carcinogenic gene $[42,52-55]$. A recent report revealed that SGK3 plays a vital role in glioblastoma as the target gene of miR212-3p [42]. To explore whether SGK3 could also promote the proliferation and metastasis of OS cells, we performed a series of assays to detect the function of SGK3. MTT assays showed that knockdown of SGK3 reduced the growth of OS cells. Transwell assays and western blotting indicated that knockdown of SGK3 suppressed the migration and invasion of OS cells via the EMT process. 


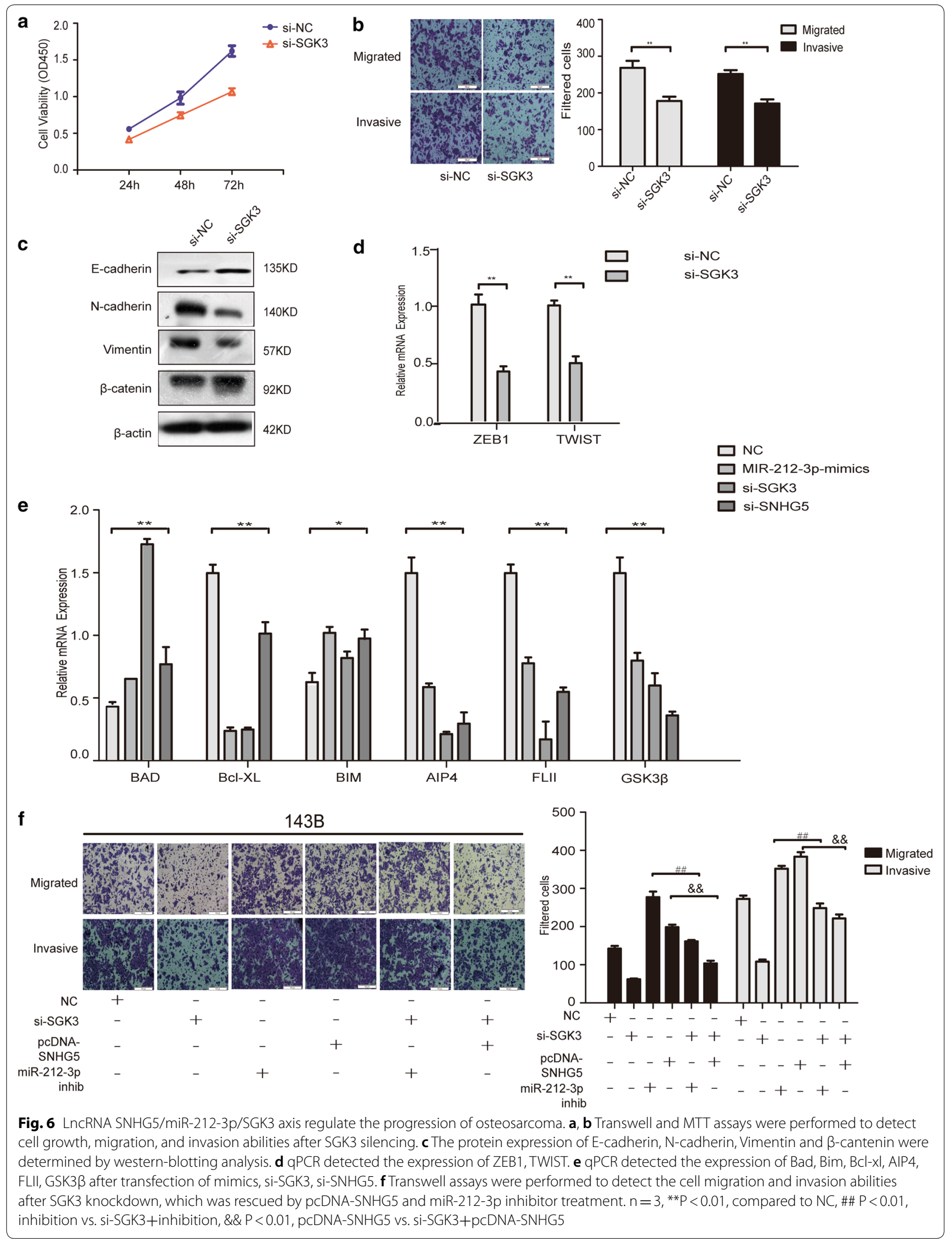




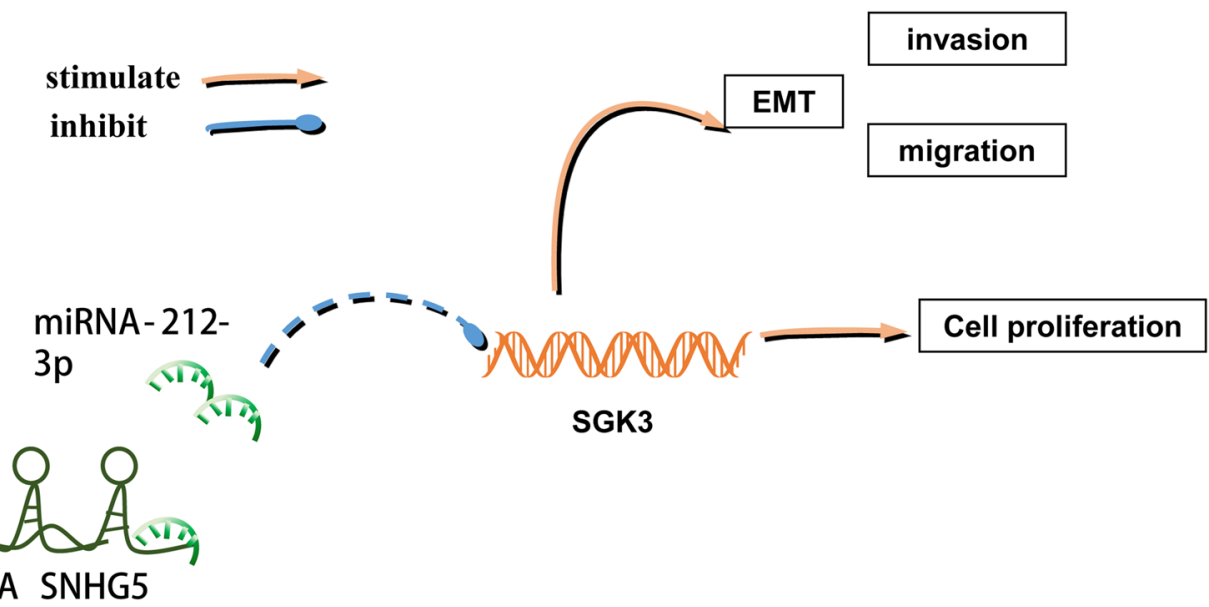

Fig. 7 Pathway diagram of LncRNA SNHG5/miR-212-3p/SGK3 axis

\section{Conclusions}

Overall, our current study demonstrated SNHG5 is involved in the regulation of OS cell progression. What is more meaningful is that SNHG5 regulated the proliferation, migration, and invasion of OS cells via the miR212-3p/SGK3 axis. Consequently, these conclusions showed that lncRNA SNHG5 plays as a critical role in OS tumorigenesis-indicating that SNHG5 may be a potential therapeutic target for osteosarcoma.

\section{Additional file}

Additional file 1: Figure S1. The function study of LnCRNA SNHG5 in MG63 and U2R OS cell.

\section{Abbreviations}

InCRNA: long non-coding RNA; SNHG5: small nucleolar RNA host gene 5; OS: osteosarcoma; qRT-PCR: quantificational real-time quantitative polymerase chain reaction

\section{Authors' contributions}

$\mathrm{CJ}$ and RZ carry out most experiments of the study and drafted the manuscript. JS, FZ, KKC and XFT clone the plasmids and perform luciferase, and qRT-PCR experiments. JZ, XL and SL carried out the statistical analysis and organized the figures. $Z Z$ and $X B L$ designed the study and associated with all the steps of the study. All authors read and approved the final manuscript.

\section{Author details}

1 Jiangxi Key Laboratory of Cancer Metastasis and Precision Treatment, The Third Affiliated Hospital of Nanchang University, 128 Xiangshan Northern Road, Nanchang 330008, Jiangxi, People's Republic of China. ${ }^{2}$ Department of Orthopedics, The Third Affiliated Hospital of Nanchang University, 128 Xiangshan Northern Road, Nanchang 330008, Jiangxi, People's Republic of China. ${ }^{3}$ Medical Department of Graduate School, Nanchang University, Nanchang 330006, Jiangxi, People's Republic of China. ${ }^{4}$ First Clinical Department, Medical School of Nanchang University, Nanchang 330006, Jiangxi, People's Republic of China.

\section{Acknowledgements}

Not applicable.

\section{Competing interests}

The authors declare that they have no competing interests.

\section{Availability of data and materials}

The datasets used and/or analyzed during the current study are available from the corresponding author upon reasonable request.

\section{Consent for publication}

Not applicable.

Ethics approval and consent to participate

Not applicable.

\section{Funding}

This study was partially sponsored by grants from the National Natural Science Foundation of China (No. 81560452 and 81672866 to XBL); the Natural Science Foundation of Jiangxi Province (No. 20161 BAB205192 and 20171ACB21073 to XBL); the Youth Science Foundation of Jiangxi Province (No. $20122 B A B 215028$ to ZPZ); Excellent Youth Foundation of Jiangxi Scientific Committee (No. 20162BCB23001 to XBL); Science and Research Fund of Jiangxi Health and Family Planning Commission (No. 20164002 to XBL); The Foundation of Nanchang Science and Technology Bureau (No. 2016 ZSCX009 to XBL); and The Yuanhang Project of Jiangxi Province to XBL.

\section{Publisher's Note}

Springer Nature remains neutral with regard to jurisdictional claims in published maps and institutional affiliations.

Received: 1 June 2018 Accepted: 10 September 2018

Published online: 18 September 2018

\section{References}

1. Hegyi M, Semsei AF, Jakab Z, Antal I, Kiss J, Szendroi M, Csoka M, Kovacs G. Good prognosis of localized osteosarcoma in young patients treated with limb-salvage surgery and chemotherapy. Pediatr Blood Cancer. 2011:57(3):415-22

2. Moore DD, Luu HH. Osteosarcoma. Cancer Treat Res. 2014;162:65-92. 
3. Luetke A, Meyers PA, Lewis I, Juergens H. Osteosarcoma treatmentwhere do we stand? A state of the art review. Cancer Treat Rev. 2014:40(4):523-32.

4. Jaffe N. Historical perspective on the introduction and use of chemotherapy for the treatment of osteosarcoma. Adv Exp Med Biol. 2014;804:1-30.

5. Aponte-Tinao L, Ayerza MA, Muscolo DL, Farfalli GL. Survival, recurrence, and function after epiphyseal preservation and allograft reconstruction in osteosarcoma of the knee. Clin Orthop Relat Res. 2015;473(5):1789-96.

6. Kung JT, Colognori D, Lee JT. Long noncoding RNAs: past, present, and future. Genetics. 2013;193(3):651-69.

7. Ling H, Vincent K, Pichler M, Fodde R, Berindan-Neagoe I, Slack FJ, Calin GA. Junk DNA and the long non-coding RNA twist in cancer genetics. Oncogene. 2015;34(39):5003-11.

8. Rigoutsos I, Lee SK, Nam SY, Anfossi S, Pasculli B, Pichler M, Jing Y, Rodriguez-Aguayo C, Telonis AG, Rossi S, et al. N-BLR, a primate-specific non-coding transcript leads to colorectal cancer invasion and migration. Genome Biol. 2017;18(1):98.

9. Wang KC, Chang HY. Molecular mechanisms of long noncoding RNAs. Mol Cell. 2011;43(6):904-14.

10. Ponting CP, Oliver PL, Reik W. Evolution and functions of long noncoding RNAs. Cell. 2009;136(4):629-41.

11. Batista PJ, Chang HY. Long noncoding RNAs: cellular address codes in development and disease. Cell. 2013;152(6):1298-307.

12. Esteller M. Non-coding RNAs in human disease. Nat Rev Genet. 2011;12(12):861-74.

13. Wapinski O, Chang HY. Long noncoding RNAs and human disease. Trends Cell Biol. 2011:21(6):354-61.

14. Dong Y, Liang G, Yuan B, Yang C, Gao R, Zhou X. MALAT1 promotes the proliferation and metastasis of osteosarcoma cells by activating the PI3K Akt pathway. Tumour Biol. 2015;36(3):1477-86.

15. Ruan W, Wang P, Feng $S, X u e Y$, Li Y. Long non-coding RNA small nucleolar RNA host gene 12 (SNHG12) promotes cell proliferation and migration by upregulating angiomotin gene expression in human osteosarcoma cells. Tumour Biol. 2016;37(3):4065-73.

16. Sun XH, Yang LB, Geng XL, Wang R, Zhang ZC. Increased expression of InCRNA HULC indicates a poor prognosis and promotes cell metastasis in osteosarcoma. Int J Clin Exp Pathol. 2015;8(3):2994-3000.

17. Xie CH, Cao YM, Huang Y, Shi QW, Guo JH, Fan ZW, Li JG, Chen BW, Wu BY. Long non-coding RNA TUG1 contributes to tumorigenesis of human osteosarcoma by sponging miR-9-5p and regulating POU2F1 expression. Tumour Biol. 2016;37(11):15031-41.

18. Cong M, Li J, Jing R, Li Z. Long non-coding RNA tumor suppressor candidate 7 functions as a tumor suppressor and inhibits proliferation in osteosarcoma. Tumour Biol. 2016;37(7):9441-50.

19. Liu Q, Huang J, Zhou N, Zhang Z, Zhang A, Lu Z, Wu F, Mo YY. LncRNA loc285194 is a p53-regulated tumor suppressor. Nucleic Acids Res. 2013;41(9):4976-87.

20. Wang $Y$, Yao J, Meng H, Yu Z, Wang Z, Yuan $X$, Chen $H$, Wang A. A novel long non-coding RNA, hypoxia-inducible factor-2alpha promoter upstream transcript, functions as an inhibitor of osteosarcoma stem cells in vitro. Mol Med Rep. 2015;11(4):2534-40.

21. Calin GA, Croce CM. MicroRNA signatures in human cancers. Nat Rev Cancer. 2006:6(11):857-66.

22. Zhang B, Pan X, Cobb GP, Anderson TA. microRNAs as oncogenes and tumor suppressors. Dev Biol. 2007;302(1):1-12.

23. Liu X, Lv XB, Wang XP, Sang Y, Xu S, Hu K, Wu M, Liang Y, Liu P, Tang J, et al. MiR-138 suppressed nasopharyngeal carcinoma growth and tumorigenesis by targeting the CCND1 oncogene. Cell Cycle. 2012;11(13):2495-506.

24. Zhang Z, Zhu Z, Watabe K, Zhang X, Bai C, Xu M, Wu F, Mo YY. Negative regulation of IncRNA GAS5 by miR-21. Cell Death Differ. 2013;20(11):1558-68.

25. Liu XH, Sun M, Nie FQ, Ge YB, Zhang EB, Yin DD, Kong R, Xia R, Lu KH, Li $J$, et al. Lnc RNA HOTAIR functions as a competing endogenous RNA to regulate HER2 expression by sponging miR-331-3p in gastric cancer. Mol Cancer. 2014;13:92.

26. Ma Z, Xue S, Zeng B, Qiu D. IncRNA SNHG5 is associated with poor prognosis of bladder cancer and promotes bladder cancer cell proliferation through targeting p27. Oncol Lett. 2018;15(2):1924-30.

27. Damas ND, Marcatti M, Come C, Christensen LL, Nielsen MM, Baumgartner R, Gylling HM. SNHG5 promotes colorectal cancer cell survival by counteracting STAU1-mediated mRNA destabilization. Nat Commun. 2016;7:13875

28. Zhao L, Guo H, Zhou B, Feng J, Li Y, Han T, Liu L, Li L, Zhang S, Liu Y, et al. Long non-coding RNA SNHG5 suppresses gastric cancer progression by trapping MTA2 in the cytosol. Oncogene. 2016;35(44):5770-80.

29. Zhao L, Han T, Li Y, Sun J, Zhang S, Liu Y, Shan B, Zheng D, Shi J. The IncRNA SNHG5/miR-32 axis regulates gastric cancer cell proliferation and migration by targeting KLF4. FASEB J. 2017;31(3):893-903.

30. He B, Bai $Y$, Kang W, Zhang $X$, Jiang $X$. LncRNA SNHG5 regulates imatinib resistance in chronic myeloid leukemia via acting as a CeRNA against MiR-205-5p. Am J Cancer Res. 2017;7(8):1704-13.

31. Ichigozaki Y, Fukushima S, Jinnin M, Miyashita A, Nakahara S, Tokuzumi A, Yamashita J, Kajihara I, Aoi J, Masuguchi S, et al. Serum long non-coding RNA, snoRNA host gene 5 level as a new tumor marker of malignant melanoma. Exp Dermatol. 2016;25(1):67-9.

32. Wang $Z$, Pan $L, Y u H$, Wang $Y$. The long non-coding RNA SNHG 5 regulates gefitinib resistance in lung adenocarcinoma cells by targeting miR-377/ CASP1 axis. Biosci Rep. 2018. https://doi.org/10.1042/BSR20180400.

33. Liao D, Zhong L, Duan T, Zhang RH, Wang X, Wang G, Hu K, Lv X, Kang T. Aspirin suppresses the growth and metastasis of osteosarcoma through the NF-kappaB pathway. Clin Cancer Res. 2015;21(23):5349-59.

34. Thiery JP, Acloque H, Huang RY, Nieto MA. Epithelial-mesenchymal transitions in development and disease. Cell. 2009;139(5):871-90.

35. Przybyla L, Muncie JM, Weaver VM. Mechanical control of epithelial-tomesenchymal transitions in development and cancer. Annu Rev Cell Dev Biol. 2016;32:527-54.

36. Guttman M, Rinn JL. Modular regulatory principles of large non-coding RNAs. Nature. 2012;482(7385):339-46.

37. Salmena L, Poliseno L, Tay Y, Kats L, Pandolfi PP. A ceRNA hypothesis: the Rosetta Stone of a hidden RNA language? Cell. 2011;146(3):353-8.

38. Diao L, Wang S, Sun Z. Long noncoding RNA GAPLINC promotes gastric cancer cell proliferation by acting as a molecular sponge of miR-378 to modulate MAPK1 expression. Onco Targets Ther. 2018;11:2797-804.

39. Wang Y, Lu Z, Wang N, Feng J, Zhang J, Luan L, Zhao W, Zeng X. Long noncoding RNA DANCR promotes colorectal cancer proliferation and metastasis via miR-577 sponging. Exp Mol Med. 2018;50(5):57.

40. Liu M, Chen L, Chan TH, Wang J, Li Y, Li Y, Zeng TT, Yuan YF, Guan XY. Serum and glucocorticoid kinase 3 at 8q13.1 promotes cell proliferation and survival in hepatocellular carcinoma. Hepatology. 2012:55(6):1754-65.

41. Vasudevan KM, Barbie DA, Davies MA, Rabinovsky R, McNear CJ, Kim $J$ J, Hennessy BT, Tseng H, Pochanard P, Kim SY, et al. AKT-independent signaling downstream of oncogenic PIK3CA mutations in human cancer. Cancer Cell. 2009;16(1):21-32.

42. Liu H, Li C, Shen C, Yin F, Wang K, Liu Y, Zheng B, Zhang W, Hou X, Chen $X$, et al. MiR-212-3p inhibits glioblastoma cell proliferation by targeting SGK3. J Neurooncol. 2015;122(3):431-9.

43. Bruhn MA, Pearson RB, Hannan RD, Sheppard KE. AKT-independent $\mathrm{PI3}$-K signaling in cancer-emerging role for SGK3. Cancer Manag Res. 2013;5:281-92

44. Hou M, Lai Y, He S, He W, Shen H, Ke Z. SGK3 (CISK) may induce tumor angiogenesis (Hypothesis). Oncol Lett. 2015;10(1):23-6.

45. Wang Y, Zhou D, Phung S, Masri S, Smith D, Chen S. SGK3 Is an estrogeninducible kinase promoting estrogen-mediated survival of breast cancer cells. Mol Endocrinol. 2011;25(1):72-82.

46. Ritter J, Bielack SS. Osteosarcoma. Ann Oncol. 2010;21(Suppl 7):vii320-5.

47. Zhang J, Yan YG, Wang C, Zhang SJ, Yu XH, Wang WJ. MicroRNAs in osteosarcoma. Clin Chim Acta. 2015:444:9-17.

48. Broadhead ML, Clark JC, Myers DE, Dass CR, Choong PF. The molecular pathogenesis of osteosarcoma: a review. Sarcoma. 2011;2011:959248.

49. Alessio N, Del Gaudio S, Capasso S, Di Bernardo G, Cappabianca S, Cipollaro M, Peluso G, Galderisi U. Low dose radiation induced senescence of human mesenchymal stromal cells and impaired the autophagy process. Oncotarget. 2015;6(10):8155-66.

50. Mao W, Sun Y, Zhang H, Cao L, Wang J, He P. A combined modality of carboplatin and photodynamic therapy suppresses epithelial-mesenchymal transition and matrix metalloproteinase-2 (MMP-2)/MMP-9 expression in HEp-2 human laryngeal cancer cells via ROS-mediated inhibition of MEK ERK signalling pathway. Lasers Med Sci. 2016;31(8):1697-705. 
51. Xie C, Chen B, Wu B, Guo J, Cao Y. LncRNA TUG1 promotes cell proliferation and suppresses apoptosis in osteosarcoma by regulating miR212-3p/FOXA1 axis. Biomed Pharmacother. 2018;97:1645-53.

52. Wu M, Huang C, Huang X, Liang R, Feng Y, Luo X. MicroRNA-144-3p suppresses tumor growth and angiogenesis by targeting SGK3 in hepatocellular carcinoma. Oncol Rep. 2017;38(4):2173-81.

53. Kong X, Liu F, Gao J. MiR-155 promotes epithelial-mesenchymal transition in hepatocellular carcinoma cells through the activation of PI3K/SGK3/ beta-catenin signaling pathways. Oncotarget. 2016;7(40):66051-60
54. Gasser JA, Inuzuka H, Lau AW, Wei W, Beroukhim R, Toker A. SGK3 mediates INPP4B-dependent PI3K signaling in breast cancer. Mol Cell. 2014:56(4):595-607.

55. Chen L, Cao Y, Rong D, Wang Y, Cao Y. MicroRNA-605 functions as a tumor suppressor by targeting INPP4B in melanoma. Oncol Rep. 2017;38(2):1276-86
Ready to submit your research? Choose BMC and benefit from:

- fast, convenient online submission

- thorough peer review by experienced researchers in your field

- rapid publication on acceptance

- support for research data, including large and complex data types

- gold Open Access which fosters wider collaboration and increased citations

- maximum visibility for your research: over $100 \mathrm{M}$ website views per year

At BMC, research is always in progress.

Learn more biomedcentral.com/submissions 